\title{
Rhizomelic chondrodysplasia punctata with isolated DHAP-AT deficiency
}

\author{
D G D Barr, J M Kirk, M Al Howasi, R J A Wanders, R B H Schutgens
}

\begin{abstract}
An infant with the characteristic phenotype of classical rhizomelic chondrodysplasia punctata was found to have an isolated deficiency of the peroxisomal enzyme acyl CoA dihydroxyacetone phosphate acyltransferase (DHAP-AT). All other peroxisomal functions measured were found to be normal. Previously described in one other case report, this confirms the existence of another distinct form of peroxisomal disorder characterised biochemically by a deficiency in de novo plasmalogen biosynthesis only.

(Arch Dis Child 1993; 68: 415-417)
\end{abstract}

Classical rhizomelic chondrodysplasia punctata (RCDP) is an autosomal recessive condition characterised clinically by severe symmetrical shortening of the proximal limb segments, stippled epiphyses and periepiphyseal calcification, facial dysmorphism, cataracts, severe failure to thrive, gross developmental retardation, and a high mortality. Peroxisomes are present in cultured fibroblasts, but several peroxisomal functions are impaired with a characteristic combined deficiency of acyl CoA dihydroxyacetone phosphate acyltransferase (DHAP-AT), DHAP-synthase, and phytanic acid oxidase coupled with the presence of an unprocessed thiolase enzyme protein.'

In the case described here, with typical RCDP phenotype, a different pattern of peroxisomal dysfunction was found.

\section{Case report}

The parents were young, healthy, unrelated, and of Saudi origin. The mother was a primigravida and had an uncomplicated pregnancy. Routine ultrasound at 30 weeks' gestation showed a short limbed fetus. Premature spontaneous labour at 32 weeks resulted in a boy with a birth weight of 2200 g. Respiratory distress syndrome required ventilatory support; jaundice was treated by phototherapy. Clinical and radiological features of RCDP were evident in the neonatal period. The patient fed poorly with a very weak suck and by 5 months of age profound growth failure (weight $3.0 \mathrm{~kg}$, length $52 \mathrm{~cm}$, head circumference $36 \mathrm{~cm}$ ) and developmental delay were evident.

Physical features included craniofacial dysmorphism with frontal bossing, a 'flat' facial profile, saddle nose, hypertelorism, long philtrum, low set ears, assymetrical crying facies, and bilateral cataracts. The limbs showed flexion deformities at knees and elbows, severe symmetrical rhizomelic shortening, ulnar deviation of the fingers and adduction of the thumb (fig 1).
There was gross psychomotor retardation with no smiling, babbling or visual fixation, complete head lag with truncal hypotonia, very poor limb movement with mild spasticity but normal reflexes, and an erratic startle response to loud sound. Radiology showed characteristic severe symmetrical rhizomelia and chondrodysplasia punctata (fig 2). The karyotype was $46 \mathrm{XY}$.

\section{BIOCHEMICAL STUDIES}

There was no abnormality of serum calcium, phosphate, magnesium, alkaline phosphatase, creatinine, or electrolytes.

Specific aspects of peroxisomal function were studied as follows:

\section{PLASMALOGEN BIOSYNTHESIS}

The activity of DHAP-AT, an essential enzyme in peroxisomal plasmalogen biosynthesis, was assayed by the method of Schutgens et al. ${ }^{2}$ DHAP-AT activity was found to be grossly

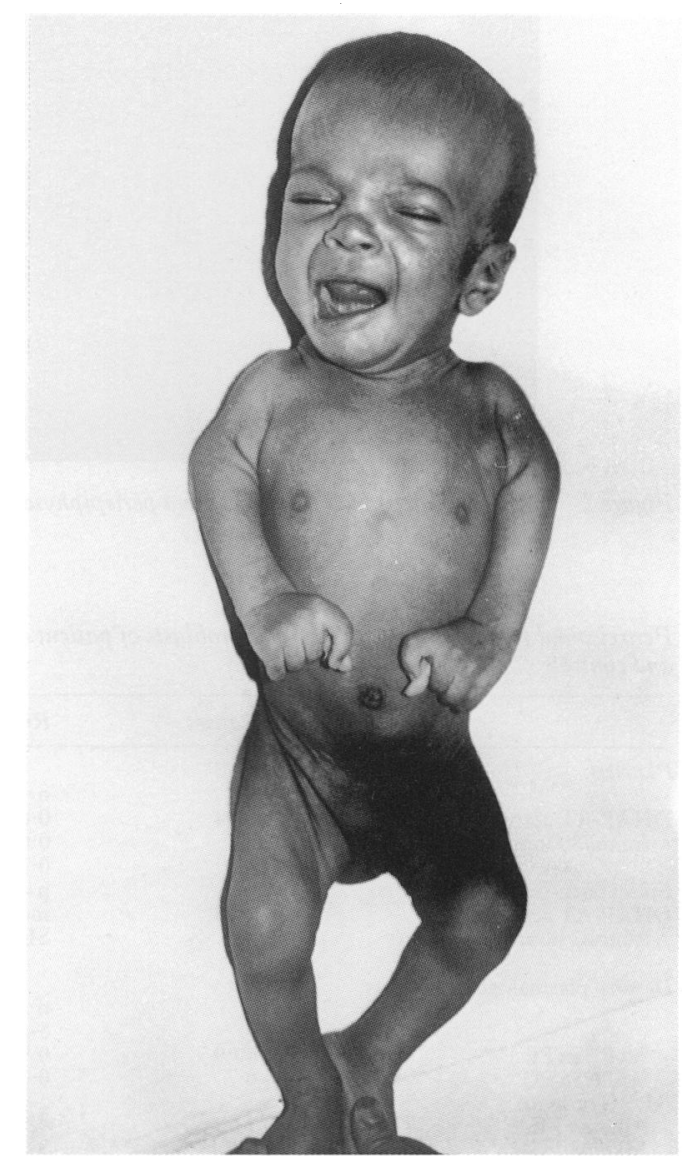

Figure I Infant with shortened proximal limb segment: flexion contractures, and craniofacial dysmorphism. 


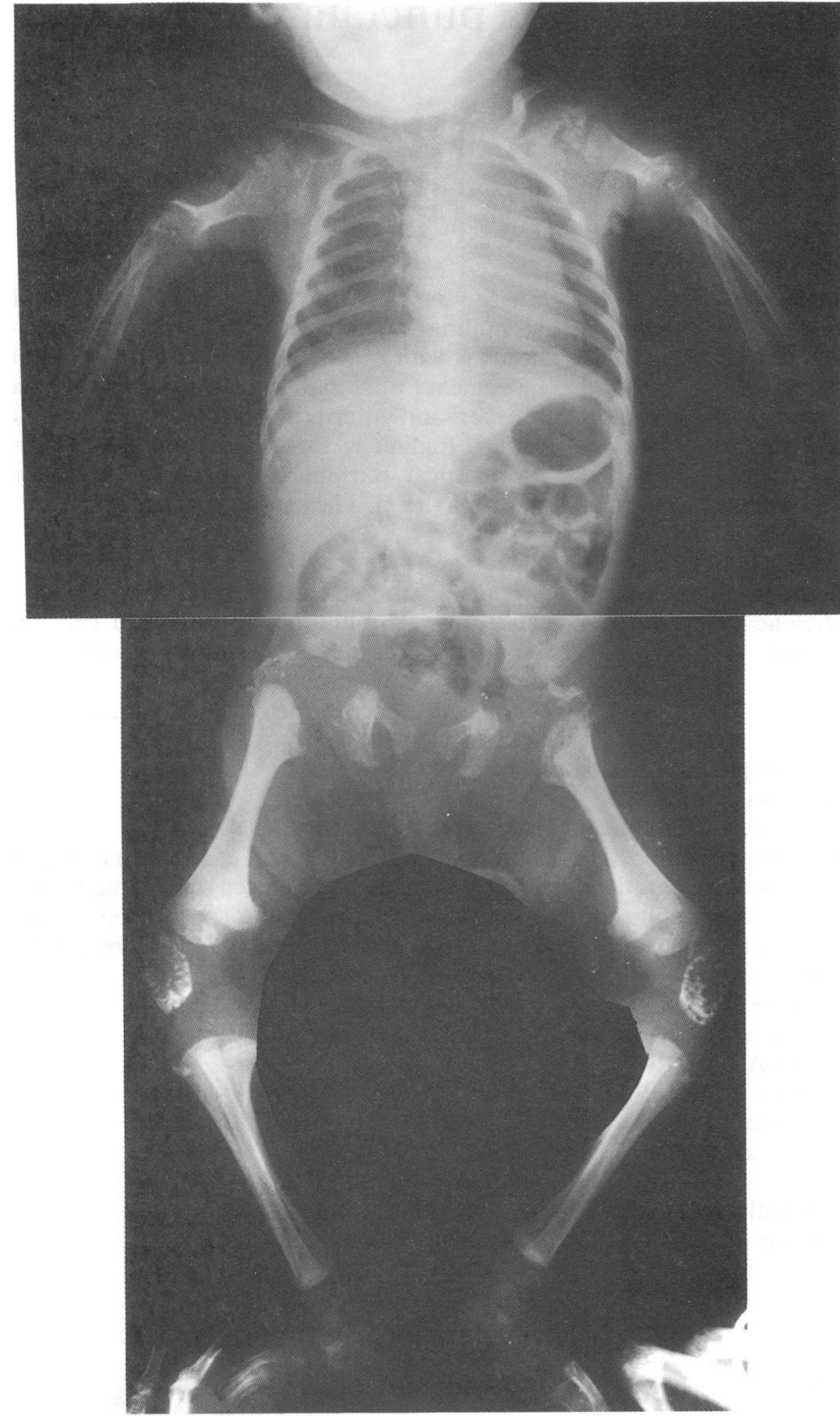

Figure 2 Rhizomelia, stippled epiphyses, and periepiphyseal calcification.

Peroxisomal functions in platelets and fibroblasts of patient compared with classical RCDP and controls

\begin{tabular}{|c|c|c|c|}
\hline & Patient & $R C D P$ & Controls \\
\hline Platelets: & & \multirow{3}{*}{$\begin{array}{l}\mathrm{n}=3 \\
0.69 \\
0 \cdot 69 \\
0 \cdot 33 \\
\mathrm{n}=11 \\
\text { mean }=1.55 \\
\mathrm{SD}=0.46\end{array}$} & \multirow{2}{*}{$\begin{array}{l}5-95 \text { th centile } \\
\mathrm{n}=47 \\
0 \cdot 9-2 \cdot 0\end{array}$} \\
\hline $\begin{array}{l}\text { DHAP-AT activity } \\
\text { (nmol } / 30 \mathrm{~min} / \mathrm{mg} \text { protein) }\end{array}$ & 0.04 & & \\
\hline $\begin{array}{l}\text { Fibroblasts: } \\
\text { DHAP-AT activity } \\
\quad(\mathrm{nmol} / 2 \text { hour/mg protein) }\end{array}$ & 0.05 & & $\begin{array}{l}\mathrm{n}=37 \\
\text { mean }=7 \cdot 0 \\
\mathrm{SD}=2 \cdot 0\end{array}$ \\
\hline De novo plasmalogen synthes & & $\mathrm{n}=13$ & $\mathrm{n}=59$ \\
\hline $\begin{array}{c}\text { \%pPE in PE } \\
\% \text { pPC in PC } \\
{ }^{3} \mathrm{H}:{ }^{14} \mathrm{C} \text { ratio in: }\end{array}$ & $\begin{array}{l}60 \cdot 9 \\
0 \cdot 7\end{array}$ & $\begin{array}{l}\text { 5-95th centile } \\
0 \cdot 9-10 \cdot 3 \\
0 \cdot 3-0 \cdot 7\end{array}$ & $\begin{array}{l}5-95 \text { th centile } \\
83-92 \\
3 \cdot 3-13 \cdot 6\end{array}$ \\
\hline $\begin{array}{l}\text { Alkenyl PE } \\
\text { Alkenyl PC }\end{array}$ & $\begin{array}{l}13 \cdot 4 \\
6 \cdot 4\end{array}$ & $\begin{array}{l}42-400 \\
3 \cdot 5-10 \cdot 7\end{array}$ & $\begin{array}{l}0.4-1 \cdot 5 \\
0.3-1.0\end{array}$ \\
\hline
\end{tabular}

$\mathrm{pPE}=$ plasmalogen phosphatidylethanolamine, $\mathrm{PE}=$ total phosphatidylethanolamine,

$\mathrm{pPC}=$ plasmalogen phosphatidylcholine, $\mathrm{PC}=$ total phosphatidylcholine . deficient in platelets and cultured fibroblasts (table), lower than found in classical RCDP, and comparable with the values found in patients with Zellweger's syndrome.

De novo plasmalogen biosynthesis, measured in cultured fibroblasts by the double labelling technique described by Schrakamp et $a l,{ }^{3}$ showed impairment of this pathway (table). Assessment of fibroblast plasmalogen concentrations by the method of Bjorkhem et $a l^{4}$ demonstrated reduced concentrations especially of C18:0 plasmalogens.

\section{PEROXISOMAL $\beta$ OXIDATION}

Both plasma and cultured fibroblasts showed normal profiles of the saturated very long chain fatty acids C24:0 and C26:0, clearly distinct from the increased concentrations found in Zellweger's syndrome.

Immunoblotting studies in cultured fibroblasts showed only the normal $41 \mathrm{kD}$ band of mature peroxisomal 3 ketoacyl CoA thiolase protein, in contrast to RCDP in which only the unprocessed $44 \mathrm{kD}$ band of the precursor protein is detectable. Studies with antiacyl CoA oxidase revealed no abnormalities.

PHYTANIC ACID METABOLISM

Plasma phytanic acid was normal at 3 months of age. Phytanic acid oxidase activity in cultured fibroblasts, as assessed by labelled carbon dioxide $\left({ }^{14} \mathrm{CO}_{2}\right)$ release from $1-{ }^{14} \mathrm{C}$ phytanic acid was found to be normal in contrast to the severe deficiency described both in patients with Zellweger's syndrome and those with classical RCDP.'

\section{Discussion}

Genetic heterogeneity in chondrodysplasia punctata is known to include severe recessive RCDP, the relatively mild autosomal dominant Conradi-Hunermann syndrome, an $\mathrm{X}$ linked dominant type only in females, and an $\mathrm{X}$ linked recessive type with a deletion of the short arm of the X chromosome.' Peroxisomal dysfunctions in classical RCDP have been characterised and compared with these other chondrodysplasia types and other peroxisomal disorders, notably Zellweger's syndrome. ${ }^{5}$ In Zellweger's syndrome a complete absence of functional peroxisomes in all tissues results in deficient activity of DHAP-AT and DHAP synthase, grossly defective peroxisomal $\beta$ oxidation of fatty acids, impaired biosynthesis of bile acids, defective $\alpha$ oxidation of phytanic acid and other metabolic abnormalities.' Classical RCDP patients demonstrate abnormal plasmalogen metabolism and phytanic acid catabolism, but functionally intact peroxisomal fatty acid oxidation, despite the absence of mature peroxisomal thiolase protein. This protein is only detectable in these patients as a $44 \mathrm{kD}$ precursor. Intact peroxisomes can be demonstrated in classical RCDP, at least in cultured fibroblasts. It has been suggested that the primary RCDP defect is at the level of a receptor or transport protein at the peroxisomal membrane. ${ }^{15}$ 
Our patient represents the second case whose clinical presentation is indistinguishable from RCDP but in whom the biochemical abnormality is limited to severe DHAP-AT deficiency. ${ }^{6}$ It therefore appears that the severe clinical abnormalities both in this patient and in classical RCDP are the direct result of the defective plasmalogen biosynthesis.

Isolated DHAP-AT deficiency appears to represent another peroxisomal disorder. Patients who present with the RCDP clinical phenotype should have detailed studies to characterise the biochemical disorder. This is necessary for prenatal diagnosis and could have implications for possible treatment.?

We thank D Broadhead and J Allen for performing DHAP-AT assays and plasma very long chain fatty acid estimations.
1 Lazarow PB, Moser HW. Disorders of peroxisome biogenesis. In: Scriver CR, Beaudet AL, Sly WS, Valle D, eds. The metabolic basis of inherited disease. 6th Ed. New York: McGraw Hill, 1989: 1479-511.

2 Schutgens RBH, Romeijn GJ, Ofman R, van den Bosch H, Tager JM, Wanders RJA. Acyl CoA: dihydroxyacetone phosphate acyl transferase in human skin fibroblasts: study of the properties using a new assay method. Biochim Biophys Acta 1986; 879: 286-91.

3 Schrakamp G, Schalkwijk CG, Schutgens RBH, Wanders RJA Tager JM, van den Bosch $\mathrm{H}$. Plasmalogen biosynthesis in peroxisomal disorders: fatty alcohol versus alkylglycerol peroxisomal disorders: fatty alcohol verst
precursors. F Lipid Res 1988; 29: 325-34.

4 Bjorkhem I, Sisfontes L, Bostrom B, Kase BF, Blomstrand R Simple diagnosis of the Zellweger syndrome by gas-liquid chromatography of dimethylacetals. F Lipid Res 1986; 27: 786-91.

5 Schutgens RBH, Heymans HSA, Wanders RJA, et al. Multiple peroxisomal enzyme deficiencies in rhizomelic chondrodysplasia punctata. Advances in Clinical Enzymology 1988; 6: $57-65$

6 Wanders RJA, Schumacher H, Hei Koop JC, Schutgens RBH, Tager JM. Human dihydroxyacetonephosphate acyltransferase deficiency: a new peroxisomal disorder. F Inherited Metab Dis 1992; 15: 389-91.

7 Holmes RD, Wilson GN, Hajra A. Oral ether lipid therapy in patients with peroxisomal disorders. 7 Inherited Metab Dis 1987; 10 (suppl 2): 239-41. 